\title{
APPROXIMATIONS FOR $i$, INTENSITY OF SELECTION
}

\author{
N. W. SIMMONDS \\ Edinburgh School of Agriculture, Edinburgh EH9 $3 \mathrm{JG}$.
}

Received 16.xii.76

\section{INTRODUGTION}

THE intensity of selection, $i$, yields an estimate of the mean, in standard deviations, of a portion of a normal curve truncated by selection. It is estimated from standard tables by the ratio $Z / p$ (Falconer, 1960) and has itself been tabulated in terms of $s$, the selection rate that determines the point of truncation. The fullest tabulation is that of Falconer (1965). In genetics, its commonest use is in calculations relating to response to selection; here, in view of the uncertainties attaching to estimates of heritability and standard deviations, great accuracy in $i$ is hardly appropriate. Easy approximations would therefore have their uses. Further, there are circumstances in which theoretical studies of response to selection in devising breeding plans would be eased by algebraic approximations for $i$. An example is provided by Smith (1969) who suggested, in an animal breeding context:

$$
i=0.8+0.41 \ln \left(\frac{1}{s}-1\right)
$$

which fits very well in a middling range of $s$. I have felt the need for approximations for $i$ in two quite different contexts: in clonal plant breeding problems and in reconstructing crop yields from selected samples, situations in which $s$ may be outside the range covered by Smith's formula. This note suggests two other approximations for $i$ which may be useful in special circumstances.

\section{Results}

Plotted against $s$, the curve of $i$ shows a pronounced flexure around $s=0 \cdot 1-0 \cdot 2$. I suggest (table 1 ) two equations covering respectively the range of general interest to plant breeders $(s<0 \cdot 1)$ and the range of interest in making minor adjustments to means $(s>0 \cdot 2)$. Neither equation covers the awkward flexure $(s=0 \cdot 1-0 \cdot 2)$ at all well but the fits in the defined ranges are excellent: at lower $s$, the error in $i$ does not exceed $0 \cdot 10$ and, at higher $s, 0 \cdot 06$. Smith's formula fits well over an intermediate range (table 1).

\section{REFERENCES}

FALCONER, D. s. 1960. Introduction to Quantitative Genetics. Edinburgh and London.

FALCONER, D. s. 1965. The inheritance of liability to certain diseases, estimated from the incidence among relatives. Ann. hum. Genet., 29, 51-76.

smrTh, c. 1969. Optimum selection procedures in animal breeding. Anim. Prod., 11, 433-42. 
TABLE 1

Approximations for intensity of selection, $\mathrm{i}$ in terms of selection rates. $\mathrm{s}$

\begin{tabular}{|c|c|c|c|c|c|}
\hline \multirow[b]{2}{*}{$s$} & \multirow[b]{2}{*}{$1 / s$} & \multirow[b]{2}{*}{$i$} & \multicolumn{3}{|c|}{ Fitted } \\
\hline & & & (1) & (2) & (3) \\
\hline $10^{-4}$ & 10000 & 3.96 & $4 \cdot 05$ & - & - \\
\hline $10^{-3.5}$ & 3162 & 3.65 & $3 \cdot 68$ & - & - \\
\hline $10^{-3}$ & 1000 & $3 \cdot 37$ & $3 \cdot 32$ & - & - \\
\hline $10^{-2.5}$ & 315 & 3.03 & $2 \cdot 95$ & - & $(3 \cdot 16)$ \\
\hline $10^{-2}$ & 100 & $2 \cdot 67$ & $2 \cdot 59$ & - & $2 \cdot 68$ \\
\hline $10^{-1.5}$ & 32 & $2 \cdot 24$ & $2 \cdot 22$ & - & $2 \cdot 21$ \\
\hline 0.05 & 20 & 2.06 & $2 \cdot 08$ & - & 2.01 \\
\hline $0 \cdot 10$ & 10 & 1.76 & 1.86 & - & 1.70 \\
\hline 0.15 & $6 \cdot 67$ & $1 \cdot 55$ & $(1.73)$ & $(1 \cdot 42)$ & 1.51 \\
\hline $0 \cdot 2,0$ & 5.00 & $1 \cdot 40$ & - & $1 \cdot 34$ & 1.37 \\
\hline 0.30 & $3 \cdot 33$ & $1 \cdot 16$ & - & $1 \cdot 17$ & $1 \cdot 15$ \\
\hline 0.40 & 2.50 & 0.97 & - & 1.00 & 0.97 \\
\hline 0.50 & $2 \cdot 00$ & $0 \cdot 80$ & - & 0.84 & 0.80 \\
\hline 0.60 & 1.67 & $0 \cdot 65$ & - & 0.67 & 0.64 \\
\hline 0.70 & $1 \cdot 43$ & 0.50 & - & $0 \cdot 50$ & 0.45 \\
\hline 0.80 & 1.25 & $0 \cdot 35$ & - & $0 \cdot 34$ & $(0.23)$ \\
\hline 0.90 & $1 \cdot 11$ & $0 \cdot 20$ & - & $0 \cdot 17$ & - \\
\hline 1.00 & 1.00 & 0 & - & 0 & - \\
\hline
\end{tabular}

Formulae: (1) $i=1 \cdot 132+0.729 \log \frac{1}{s}$

(Effective range, $s=10^{-4} \ldots 10^{-1}$ )

(2) $i=1.672-1.670 \mathrm{~s}$

(Effective range, $s=0.20 \ldots 1 \cdot 00$ )

(3) $i=0 \cdot 8+0 \cdot 41 \ln \left(\frac{1}{s}-1\right)$

(Smith's formula: effective range, $s=0.004 \ldots 0 \cdot 75$ ) 